\title{
Violência contra as mulheres: atuação da enfermeira na atenção primária à
} \section{saúde}

Violence against women: nurse's performance in primary health care

Violencia contra las mujeres: actuación de la enfermera en la atención primaria de la salud

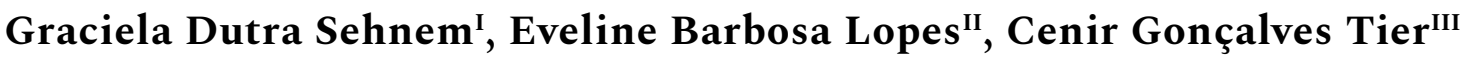 Aline Cammarano Ribeiro ${ }^{\mathrm{V}}$, Victória de Quadros Severo Macielv $^{\mathrm{V}}$ Lara Castilhos ${ }^{\mathrm{VI}}$}

\begin{abstract}
Resumo: Objetivo: conhecer a atuação da enfermeira nas Estratégias Saúde da Família frente à violência contra as mulheres. Método: pesquisa qualitativa, descritiva, realizada em Estratégias Saúde da Família de um município do Rio Grande do Sul, em 2017. Realizaram-se entrevistas semiestruturadas e aplicação de vinheta com enfermeiras, e os dados analisados à proposta operativa de Minayo. Resultados: o vínculo, o acolhimento e a notificação compulsória constituíram fatores importantes para a atuação junto às mulheres em situação de violência. A falta de abordagem do tema na formação acadêmica e profissional e a desarticulação da rede de atenção foram identificadas como condições que dificultam à atenção. Conclusão: essa investigação aponta para a necessidade de discussões da temática nos espaços acadêmicos e nos serviços e a integração e articulação da rede de atenção.
\end{abstract}

Descritores: Violência contra a mulher; Estratégia saúde da família; Enfermagem

\begin{abstract}
Objective: to understand nurse practice in primary health care about violence against women. Method: qualitative study, descriptive, develop at Family Health Strategy of a city of state of Rio Grande do Sul in 2017. It was used semi-structured interviews and vignette with nurses, data analysis was operative protocol of Minayo. Results: the receptiveness, links and the compulsory notification are important points to practice with woman violence
\end{abstract}

\footnotetext{
I Enfermeira. Doutora em Enfermagem. Professora Adjunta do Departamento de Enfermagem e do Programa de Pós-Graduação em Enfermagem da Universidade Federal de Santa Maria (UFSM). Santa Maria, RS, Brasil. Email: graci_dutra@yahoo.com.br ORCID: https://orcid.org/0000-0003-4536-824X

II Enfermeira. Graduada em Enfermagem. Enfermeira no Hospital Santa Casa de Caridade de Uruguaiana. Uruguaiana, RS, Brasil. Email: eveline.bl@hotmail.com ORCID: https://orcid.org/0000-0001-8263-6093

III Enfermeira. Doutora em Enfermagem. Professora Adjunta do Curso de Enfermagem da Universidade Federal do Pampa (UNIPAMPA). Uruguaiana, RS, Brasil. Email: cgtier@gmail.com ORCID: https:/orcid.org/0000-0003-1539-7816

IV Enfermeira. Doutora em Enfermagem. Professora Adjunta do Departamento de Enfermagem e do Programa de Pós-Graduação em Enfermagem da Universidade Federal de Santa Maria (UFSM). Santa Maria, RS, Brasil. Email: alinecammarano@gmail.com ORCID: https://orcid.org/0000-0003-3575-2555

v Acadêmica de Enfermagem. Universidade Federal de Santa Maria (UFSM). Santa Maria, RS, Brasil. Email: victoriatrabalhos@outlook.com ORCID: https://orcid.org/0000-0003-1959-7639

VI Enfermeira. Mestranda do Programa de Pós-Graduação em Enfermagem da Universidade Federal de Santa Maria (UFSM). Santa Maria, RS, Brasil. Email: laracastilhos23@gmail.com ORCID: https://orcid.org/0000-0003-2845-973X
} 
situation. The lack of approach about theme in academic formation and profissional and disarticulation of the care network are difficult condicions to care. Conclusion: This investigacion show the needs of discussion about the theme in academic and services sceneries and integration and articulation of the care network.

Descriptors: Violence against women; Family health strategy; Nursing

Resumen: Objetivo: conocer la actuación de la enfermera ${ }^{1}$ en las Estrategias Salud de la Familia ante la violencia contra las mujeres. Método: investigación cualitativa, descriptiva, realizada en Estrategias Salud de la Familia de un municipio de Rio Grande do Sul, en 2017. Se realizaron entrevistas semiestructuradas y aplicación de viñetas con enfermeras, y los datos se analizaron por la propuesta operativa de Minayo. Resultados: el vínculo, la acogida y la notificación obligatoria constituyeron factores importantes para la actuación junto a las mujeres en situación de violencia. La falta de enfoque del tema en la formación académica y profesional y la desarticulación de la red de atención fueron identificadas como condiciones que dificultan la atención. Conclusión: esta investigación apunta la necesidad de discusiones de la temática en espacios académicos y servicios y la integración y articulación de la red de atención.

Descriptores: Violencia contra la mujer; Estrategia de salud familiar; Enfermería

\section{Introdução}

A Organização Mundial da Saúde revelou que em 2019, mundialmente, 30\% das mulheres já experimentaram violência física e/ou sexual por um parceiro íntimo. Além disso, que meninas jovens e mulheres pertencentes a determinadas etnias, transsexuais e com deficiência enfrentam maior risco de diferentes formas de violência. A violência contra as mulheres é uma violação dos direitos humanos, está enraizada na desigualdade de gênero, constitui um problema de saúde pública e um impedimento ao desenvolvimento social. ${ }^{1}$

Acerca dos dados mundiais, uma revisão sistemática evidenciou que a violência sexual contra as mulheres apresenta níveis endêmicos em algumas áreas, como, por exemplo, nas regiões central e sul da África Subsaariana e há uma menor prevalência no sul da Ásia. ${ }^{2}$ No Brasil, 23\% das mulheres estão sujeitas à violência doméstica, a forma mais recorrente da violência de gênero na esfera privada, sendo que $70 \%$ desses crimes contra as mulheres ocorrem dentro de casa e são praticados pelo próprio companheiro ou marido. ${ }^{3}$

A violência de gênero na relação amorosa revela a existência do controle do homem sobre o corpo, a sexualidade e a mente feminina, reiterando a diferença que se estabelece entre homens e mulheres na sociedade, e, também, a manutenção de poder e dominação disseminadas 
3 | Sehnem GD, Lopes EB, Tier CG, Ribeiro AC, Maciel VQS, Castilhos L

na ordem patriarcal. Esta relação de poder também pode ser observada nas relações familiares, reafirmando a violência de gênero. ${ }^{4}$

Como subsídio para o enfrentamento à violência contra as mulheres, foi implementada, em âmbito nacional, a Política Nacional de Enfrentamento à Violência contra as Mulheres. ${ }^{5}$ Esta política está subsidiada em eixos estruturantes, quais sejam, prevenção, enfrentamento e combate, assistência e acesso e garantia de direitos e tem por finalidade estabelecer conceitos, princípios, diretrizes e ações de prevenção e combate à violência contra as mulheres, assim como de assistência e garantia de direitos às mulheres em situação de violência. A Política Nacional encontra-se, também, em consonância com a Lei no 11.340/2006 (Lei Maria da Penha). ${ }^{5}$

Os prejuízos às mulheres que vivenciam a violência são, geralmente, vastos, causando danos físicos, psicológicos e afetando a qualidade de vida. É importante salientar que a violência psicológica é raramente percebida pelos profissionais da saúde, por não deixar marcas físicas, mas é um fator para o adoecimento. Esta forma de violência compromete a saúde mental da mulher, de forma a acarretar distúrbios na sua habilidade de se comunicar e de reconhecer seus recursos para o cumprimento de tarefas em sua vida. O isolamento social é uma das suas principais formas de manifestação, no qual o companheiro busca afastar a mulher de seu convívio social, proibindo-a de manter relacionamento com seus familiares e amigos, trabalhar ou estudar. ${ }^{6}$

A caminhada das mulheres no trajeto de tentar interromper o ciclo de violência é ambivalente, não se trata apenas de questões institucionais, mas estrutura-se no papel da mulher na sociedade em consenso com suas necessidades e decisões. Desta maneira, reconhecese que as razões que levam as mulheres a denunciarem o companheiro, em uma relação permeada pela violência, envolvem medos e preocupações com os filhos e o feminicídio. ${ }^{7}$

Acerca disso, estudo evidenciou que a rede primária de mulheres que denunciam o vivido da violência por parceiro íntimo, mesmo embasada em relações sociais significativas, 
Violência contra as mulheres: atuação da enfermeira na atenção primária à saúde |4

demonstrou, por vezes, suporte limitado na situação de violência. ${ }^{8}$ Ademais, a pouca autonomia financeira para gerir sua vida e de seus filhos, pode levar a mulher a seguir no relacionamento indesejado com o companheiro. Demonstrou, também, que os serviços que compõem a rede de atendimento às mulheres em situação de violência não são reconhecidos como ajuda efetiva para suas demandas sociais e de saúde, revelando uma rede fragmentada e desarticulada, distante da realidade vivencial das mulheres. ${ }^{8}$

Pesquisa atual apontou a necessidade de reforçar as ações que os profissionais de saúde já desenvolvem na atenção primária à saúde, como o acolhimento e a escuta. ${ }^{9}$ No que tange o acolhimento, este precisa ser realizado desde o momento em que a mulher acessa o serviço de saúde, até que suas necessidades sejam atendidas de modo integral neste, ou que seja encaminhada para outro local dentro da rede de atenção à saúde. ${ }^{9}$ Contudo, mesmo constatando que a violência de gênero é considerada como demanda pelos profissionais das unidades de atenção primária, outro estudo refere que eles não se sentem à vontade para abordar o assunto com as usuárias e, alguns, nunca questionaram sobre esta problemática, mantendo-a velada. ${ }^{10}$

A respeito disso, evidências apontam que os profissionais atuantes na atenção primária têm dificuldade em tratar do tema da violência contra as mulheres, sentindo-se despreparados para tal abordagem. ${ }^{10-11}$ Isso representa dizer que a ausência deste conhecimento faz com que o cuidado a estas mulheres ocorra de forma fragmentada, na qual são valorizadas apenas as questões clínicas e não as demandas sociais que perpassam a violência.

Considerando este contexto, o presente estudo buscou responder ao seguinte questionamento: de que forma acontece a atuação da enfermeira* nas Estratégias Saúde da Família frente à violência contra as mulheres? Para responder a esta questão, objetivou-se conhecer a atuação da enfermeira nas Estratégias Saúde da Família frente à violência contra as mulheres.

\footnotetext{
* Devido ao quantitativo de profissionais de enfermagem, nesta pesquisa, ser majoritariamente feminino, justifica-se a utilização do substantivo no feminino.
} 
5 | Sehnem GD, Lopes EB, Tier CG, Ribeiro AC, Maciel VQS, Castilhos L

\section{Método}

Estudo descritivo com abordagem qualitativa, realizado em Estratégias Saúde da Família (ESF) da área urbana de um município da fronteira oeste do Rio Grande do Sul/Brasil, no segundo semestre de 2017. Justifica-se o cenário de coleta a ESF pois constituem a porta de entrada e comunicação dos usuários com toda a rede do SUS.

Participaram 11 enfermeiras das referidas ESF. Para o dimensionamento da quantidade de participantes seguiu-se a orientação de que quando a amostra é ideal, ela reflete, em quantidade e intensidade, as múltiplas dimensões de determinado fenômeno e busca a qualidade das ações e das interações em todo o decorrer do processo. ${ }^{12} \mathrm{~A}$ inclusão das participantes seguiu os seguintes critérios: ser enfermeira e estar vinculada às ESF da rede de atenção primária do município supracitado. Foram excluídas profissionais que estivessem afastadas por férias ou licenças.

As enfermeiras foram convidadas pessoalmente a participar do estudo. Nesta ocasião, foram apresentados o objetivo e a metodologia da pesquisa com o esclarecimento das dúvidas e foi combinada uma data para a realização da entrevista, conforme a disponibilidade de cada profissional.

A produção de dados foi realizada por meio de entrevistas semiestruturadas, com um roteiro previamente definido, seguidas pela utilização de uma vinheta. Esta consistiu em uma descrição curta de uma situação fictícia, na qual as respondentes foram solicitadas a reagir. As entrevistas foram conduzidas individualmente nos espaços das ESF. Todas as informações obtidas foram registradas em um gravador digital, mediante autorização, e transcritas de maneira integral.

Para análise dos dados adotou-se a proposta operativa de Minayo. ${ }^{13} \mathrm{O}$ primeiro nível se refere à fase exploratória. Tal momento, foi marcado pela compreensão do contexto do grupo social pesquisado, perfazendo a caracterização do mesmo no que se refere ao sexo, faixa etária, 
Violência contra as mulheres: atuação da enfermeira na atenção primária à saúde |6

tempo de experiência profissional e de atuação em unidades de saúde e cursos de pósgraduação. Em seguida, percorreu-se o segundo nível, denominado de interpretativo. Nesta etapa, ocorreu o encontro com os depoimentos das participantes e buscou-se identificar nos relatos o sentido, a lógica interna, as projeções e as interpretações acerca do tema investigado. Ainda, a fase interpretativa foi dividida em ordenação e classificação dos dados, respectivamente. A ordenação incluiu a transcrição e a organização destes em categorias empíricas. Na classificação, realizou-se uma leitura exaustiva da literatura para discutir com os achados e se deu a construção do relatório da pesquisa.

A pesquisa seguiu os preceitos da Resolução nº. 466 de 2012 do Conselho Nacional de Saúde do Ministério da Saúde e obteve aprovação do Comitê de Ética em Pesquisa da Universidade Federal do Pampa, CAAE 69364017.7.0000.5323, parecer nº 2.168.674, em 11/07/2017. Como garantia ao anonimato das participantes, as enfermeiras foram identificadas pela letra E seguida de números: E1, E2, E3 (...) E11. Previamente a gravação de voz foi solicitada a autorização e assinatura do Termo de Consentimento Livre e Esclarecido.

\section{Resultados e discussão}

Participaram do estudo enfermeiras com predomínio do sexo feminino, sendo dez mulheres e um homem, que se encontravam na faixa etária entre 23 a 55 anos. O tempo de experiência profissional foi de quatro a dezesseis anos. Já, o tempo de atuação em unidades de saúde foi de seis meses a cinco anos. No que se refere à pós-graduação latu sensu, apresentaram especialização em medicina do esporte (uma), ciências da saúde (uma), saúde da família (duas), saúde pública (três), e saúde mental (um). Além disso, referiram possuir mestrado em bioquímica (uma) e saúde coletiva (uma). 
7 | Sehnem GD, Lopes EB, Tier CG, Ribeiro AC, Maciel VQS, Castilhos L

A partir da análise temática dos dados emergiram duas categorias, sendo elas: Fatores que facilitam a atuação da enfermeira às mulheres em situação de violência e Condições que dificultam a atuação da enfermeira às mulheres em situação de violência.

\section{Fatores que facilitam a atuação da enfermeira às mulheres em situação de violência}

Assistir à saúde de mulheres em situação de violência envolve fatores multidimensionais, os quais determinam a qualidade da assistência. Dentre os fatores que facilitam a assistência a estas mulheres na atenção primária em saúde, identificou-se o vínculo das usuárias com a equipe de saúde como essencial para a prevenção e enfrentamento da violência.

Eu acredito que um dos pontos positivos é o vínculo que a gente já vem criando [...] elas se sentem muito acolhidas, elas conseguem manter esse vínculo para chegar e expor uma situação, tanto com a enfermagem quanto com os agentes [comunitários] de saúde. (E 1)

Já vivenciei várias situações e é aquilo que eu te disse, a importância do vínculo e da gente mostrar para ela que a gente está aqui para ajudar. (E 4) A facilidade é o vínculo que as pacientes têm, elas confiam, então é mais fácil. (E 7)

Nas falas das enfermeiras percebe-se a importância desta correlação, pois favorece a procura das usuárias pelo serviço de saúde, sendo uma conexão importante para que adquiram confiança e possam tanto esclarecer dúvidas sobre a sua saúde quanto expor problemas familiares na procura de compreensão, auxílio e atitude para enfretamento do problema. Assim, as práticas de cuidado a tais mulheres necessitam estar alicerçadas na escuta e na corresponsabilização, com ações que possam contribuir romper com a da situação de violência. Essas ações precisam estar de acordo com as demandas dessas mulheres, ou seja, para além das questões físicas, também é preciso direcionar a atenção às necessidades econômicas, sociais e emocionais. $^{6}$ 
Violência contra as mulheres: atuação da enfermeira na atenção primária à saúde $\mid 8$

As falas das enfermeiras sinalizam que o vínculo é importante e pode ser um facilitador para atuar com as mulheres em situação de violência, no entanto, estudo realizado com enfermeiros que atuam em Unidades de Estratégias Saúde da Família de Porto Alegre, Rio Grande do Sul, mostrou fragilidade na sua construção. No referido contexto, a troca frequente de profissionais nos serviços de saúde fragiliza o vínculo, pois trata-se de um assunto que muitas mulheres sentem vergonha de compartilhar com o outro. ${ }^{14}$

Algumas participantes relataram ainda que, além do vínculo, umas das estratégias que colaboram para facilitar a assistência é o acolhimento. Isso pode ser identificado a seguir.

Tem que estabelecer uma relação de confiança através do acolhimento. (E 3)

A gente faz um atendimento mais acolhedor, também, pelo fato da gente ser mulher. Tem sentimento envolvido. (E 4)

Quando a gente se depara com esses casos, a gente tem que ter empatia, se colocar no lugar dela e ver de que maneira tu podes auxiliar, seja acompanhando, conversando, colocando o que o serviço tem à disposição.

Estudo sobre as concepções e ações dos profissionais de saúde acerca da rede de atenção às mulheres em situação de violência, considerou que o acolhimento e a escuta precisam ser fortalecidos. ${ }^{9}$ O acolhimento precisa ser realizado em todos os momentos, desde a chegada dessa mulher em situação de violência, até os seus possíveis encaminhamentos para outros locais de atendimento, na direção de atender todas as suas necessidades. ${ }^{9}$

Diante das difíceis situações de violência, é preciso pensar em ideias que favoreçam o atendimento a essas mulheres, como falar das potencialidades delas que não estejam somente relacionadas à violência. ${ }^{15}$ Assim, refletir acerca de possibilidades para o futuro, da relação com os filhos e de suas relações de amizades e familiares, pode auxiliar a retomar a autoestima. ${ }^{15}$ Cabe instigar essas mulheres a se sentirem empoderadas com suas escolhas e história de vida. 
9 | Sehnem GD, Lopes EB, Tier CG, Ribeiro AC, Maciel VQS, Castilhos L

Para a enfermeira realizar um atendimento acolhedor é interessante olhar para as diferentes faces da violência, sendo que para isso se faz necessária uma preparação profissional pautada em discussões integradas e interdisciplinares. ${ }^{16}$ Também, as qualificações profissionais são importantes na direção de proporcionar um cuidado acolhedor e integral, potencializando a construção de vínculos. ${ }^{16}$

A unidade de atenção básica está entre os serviços procurados por essas mulheres para tratar questões agudas de sua saúde e da sua família, nesses momentos em que busca o serviço, caso se sinta acolhida e segura, pode revelar situações de violência. No entanto, algumas vezes, essas mulheres não revelam o desencadeador dessas situações, assim cabe aos profissionais estarem atentos, para identificar e realizar possíveis cuidados e encaminhamentos necessários. ${ }^{6}$

No que se refere ao atendimento acolhedor, justificado por ser uma enfermeira cuidando de outra mulher, considera-se que isso se deve à possibilidade de aproximar algumas vivências e expectativas. Isso pode propiciar que a mulher em situação de violência sinta-se à vontade para falar sobre suas angústias e medos mais íntimos com outras mulheres. Esse depoimento reflete a sororidade, que se caracteriza como uma experiência subjetiva entre mulheres na busca por relações igualitárias, na construção de alianças existenciais e políticas com outras mulheres e para contribuir com a eliminação social de todas as formas de opressão. ${ }^{17}$

Quando detectada uma situação de violência de gênero, as enfermeiras identificaram a necessidade da realização da notificação compulsória, na qual a violência é registrada no Sistema de Informações sobre Agravos de Notificação, como pode ser observado a seguir.

A gente tem uma notificação quando ocorre violência, que tem que ser preenchida, também. A violência tem que ser notificada. (E 3)

Quando elas são identificadas a gente faz uma notificação que é entregue na vigilância epidemiológica, notifico o CREAS [Centro de Referência Especializado de Assistência Social] e a polícia [delegacia da mulher], também. (E 6) 
Violência contra as mulheres: atuação da enfermeira na atenção primária à saúde | 10

Faço a notificação que vai para vigilância epidemiológica e depois busco sempre uma resposta dos encaminhamentos que foram feitos nos setores. (E 9)

No que tange os direitos legais, a ampliação das taxas de violência contra as mulheres resultou na criação de legislações específicas, como a lei federal 10.778/2003 que estabelece a notificação compulsória desses casos, sejam elas atendidas em serviços de saúde públicos ou privados. ${ }^{18} \mathrm{~A}$ notificação é uma ligação entre o serviço de saúde e o espaço legal, constituindo-se em uma ação integrada que possibilita atuações mais efetivas. Afirma-se a importância da notificação para fundamentar a assistência realizada e promover a redução dessas situações de violência, bem como prevenir problemas mais sérios às pessoas que a vivenciam. ${ }^{19}$

Pesquisa realizada em um município do noroeste do Rio Grande do Sul revela que, aproximadamente, $40 \%$ dos profissionais de saúde, atuantes na atenção primária, não sabiam sobre a prática desta notificação, sendo sinalizada, na referida pesquisa, a necessidade de explicações para o desenvolvimento dessa prática. ${ }^{10}$ Assim, a ausência da notificação compulsória, remete a importância e a necessidade de qualificar essa prática, a partir do conhecimento, uma vez que, se o profissional que não busca se qualificar se exime de seus deveres profissionais. ${ }^{20}$ Reitera-se que a notificação compulsória da violência é realizada em casos suspeitos e confirmados, porém alguns profissionais de saúde sentem-se apreensivos para realizar as notificações de violência. ${ }^{9}$

\section{Condições que dificultam a atuação da enfermeira às mulheres em situação de violência}

Tratar de violência é algo complexo que necessita de uma abordagem qualificada, porém, muitas vezes, é incipiente nos espaços acadêmicos e profissionais discussões acerca do tema, o que pode refletir em práticas inadequadas e frágeis estratégias de prevenção. Para tanto, há 
11 | Sehnem GD, Lopes EB, Tier CG, Ribeiro AC, Maciel VQS, Castilhos L

fatores que dificultam o atendimento às mulheres em situação de violência, sendo um deles o despreparo dos profissionais.

Capacitada para esse atendimento não estou, até porque não tivemos uma educação permanente sobre o assunto. (E 2)

Não me sinto capacitada, porque é um assunto que a gente não vivencia todos os dias, na academia não tem esse preparo, é uma coisa que tem que ir buscando com o tempo. (E 3)

Das dificuldades do atendimento tenho o sentimento de não estar devidamente capacitada. (E 5)

Nunca tivemos uma capacitação para atender essas mulheres, vai muito da vivência mesmo, que com o passar do tempo acabamos aprendendo. (E 6)

Não me sinto preparada, sinto falta de capacitações, porque é uma situação rotineira e não somos preparados para enfrentar. (E 10)

Observa-se que a falta de preparo tem origem na graduação, sendo a violência um tema pouco abordado no contexto da formação acadêmica. Isso contínua após, na vida profissional, considerando que os espaços de gestão e gerência, muitas vezes, não promovem discussões e qualificação para o desenvolvimento de uma abordagem qualificada.

Estudo realizado para identificar a relação entre a formação profissional e a notificação da violência contra as mulheres mostrou, em seus resultados, que para grande parte dos profissionais de saúde esse tema não foi discutido na graduação e na pós-graduação e os demais entrevistados, que manifestaram contato com o tema, referiram que ocorreu de maneira breve. ${ }^{21}$ Pesquisa relata a experiência da introdução de uma disciplina específica sobre a violência no curso de graduação em enfermagem como positiva, pois propicia amplas discussões sobre o tema, com reflexões acerca das construções culturais que circundam a temática e da desmistificação do assunto. ${ }^{22}$

Dessa forma, para ocorrer uma abordagem às mulheres em situação de violência, de maneira integral, há necessidade de qualificações contínuas, fundamentadas nas políticas e 
Violência contra as mulheres: atuação da enfermeira na atenção primária à saúde | 12

práticas em saúde. A partir disso, a enfermeira junto à equipe de saúde terá subsídios de identificar situações de violência para além do serviço de saúde. ${ }^{11}$ Destaca-se para a importância da qualificação profissional no contexto da atenção primária à saúde, pois evidencia-se que as ações desenvolvidas nesse contexto, acerca da violência, ainda são frágeis e com pouca resolutividade. ${ }^{23}$

Dentre os fatores que dificultam a atenção às mulheres em situação de violência de gênero está a identificação destas, pois é necessário ter um olhar sensível para desvelar essas mulheres no serviço e qualificado para desenvolver a abordagem e os cuidados necessários. Algumas falas das entrevistadas expressam essa dificuldade:

É muito difícil, na primeira vez, elas já falarem alguma coisa, a gente não identifica de cara. (E 3)

Eu acho que é uma coisa que fica muito dentro das casas, do espaço privado, não chega até a unidade. Então, é difícil identificar. (E 6)

A dificuldade de identificar os casos de violência contra as mulheres pelas enfermeiras está relacionada, muitas vezes, por serem situações configuradas como íntimas, as quais concentram-se em seus domicílios. As relações dessas mulheres são restritas, dessa forma se protegem de julgamentos relacionados as suas decisões, principalmente, no que se refere a manter o convívio com o agressor. ${ }^{8}$

Tais mulheres desenvolvem isolamento, afastam-se de suas relações de amizade e familiar, o que é desencadeado por sentirem-se tristes, envergonhadas, com medo, sem autoestima e com dependência econômica. Devido ao isolamento, apresentam um número reduzido de pessoas que possam ajudá-las quando necessitam. ${ }^{6}$ Assim, o ciclo da violência se mantém, associado a fragilidades emocionais, a dependência econômica do companheiro e, por vezes, a acreditarem que o comportamento dele pode ser modificado. ${ }^{24}$ 
13 | Sehnem GD, Lopes EB, Tier CG, Ribeiro AC, Maciel VQS, Castilhos L

Destaca-se que, muitas vezes, as situações de violência, nos serviços de atenção primária, não são abordadas, os profissionais apresentam limitações para conduzirem situações que se caracterizam da esfera íntima por acreditarem que não podem realizar interferências nessas vivências, o que ocasiona a invisibilidade da violência e reflete uma prática profissional fragilizada. ${ }^{23}$ Importante o profissional ter clareza de sua função e o compromisso com a mulher em situação de violência e com a sua família, desmistificando conceitos e práticas já estabelecidos em seu cotidiano, agregando conhecimento científico, além de altruísmo e sensibilidade.

Diante das dificuldades de identificar as situações de violência no serviço de saúde, temse a visita domiciliar como ferramenta a ser utilizada pelos profissionais de saúde, principalmente, pelo agente comunitário de saúde, para a identificação dessas situações. ${ }^{9}$ Ainda, a visita domiciliar possibilita a formação de um elo entre profissional e usuária, como um recurso que permite a observação do contexto e o estabelecimento de vínculo, principalmente, pela omissão das mulheres em falar dos ocorridos. ${ }^{11}$

Para além da atuação da enfermeira, é necessário a existência de setores integrados para garantir um atendimento adequado e humanizado a estas mulheres. As falas, a seguir, elucidam a a vivência das enfermeiras em casos de violência.

Algumas dificuldades que a gente tem estão relacionadas à rede não funcionar, isso fragiliza o atendimento. (E 4)

A gente encaminha e não tem um retorno, tem que ir atrás, não tem uma resolutividade boa. (E 8 )

Os encaminhamentos são demorados, as articulações de rede são demoradas. (E 9)

Não tenho contato com a delegacia da mulher. (E10)

Por meio das falas observa-se a descontinuidade do cuidado e destaca-se a importância da constituição de uma rede de atendimento às mulheres em situação de violência, a qual 
Violência contra as mulheres: atuação da enfermeira na atenção primária à saúde | 14

precisa estar fundamentada na integração de múltiplas áreas do conhecimento e com diálogos nos diferentes setores. ${ }^{25}$ Ressalta-se que compor uma rede é algo complexo e necessário, pois envolve múltiplos fatores, para tanto, pondera-se a viabilização da comunicação entre os espaços que essa mulher transita, em que os profissionais precisam ser comprometidos e articulados para promoverem a continuidade do cuidado. ${ }^{25}$

As dificuldades apresentadas pelas participantes como a falta de contato, morosidade de encaminhamentos e articulações, remetem a fragilidade do atendimento a essas mulheres. Considera-se imprescindível buscar estratégias que assegurem um atendimento adequado, pois as mulheres em situação de violência precisam ser assistidas em suas vulnerabilidades, encontrando segurança, proteção e resolutividade nos serviços de saúde para si e para sua família.

\section{Conclusão}

O estudo evidenciou potencialidades e fragilidades quanto à atuação das enfermeiras, no cenário da atenção primária, junto às mulheres que vivenciam violência de gênero. Constatou-se que o vínculo das usuárias com a unidade de saúde e o acolhimento são fatores essenciais para o planejamento de cuidados às mulheres que vivenciam esta situação. Ademais, a notificação compulsória foi identificada como agente potencializador para o processo de enfrentamento e prevenção a violência e articulação entre os serviços.

As enfermeiras relataram não se sentirem preparadas para atendere situações de violência contra as mulheres, este sentimento se origina da ausência de abordagem deste tema na formação acadêmica, o que se perpetua na vida profissional. Isto, pode refletir na identificação desses casos e no manejo adequado dos mesmos. Também, foi identificada a desarticulação dos serviços de atendimento como condição que dificulta à atenção a esta população, impossibilitando o acompanhamento e a resolutividade dos casos de violência identificados. 
15 | Sehnem GD, Lopes EB, Tier CG, Ribeiro AC, Maciel VQS, Castilhos L

A partir desse estudo entende-se a importância da enfermagem em sua prática mobilizar as mulheres para a construção da igualdade de gênero e de sua autonomia, ultrapassando o tecnicismo e a orientação meramente protocolar. Esta mirada para a prática profissional trata-se de uma perspectiva ética e política, que pressupõe compreender a saúde das mulheres a partir de uma perspectiva emancipadora.

Este estudo teve como limitação apresentar apenas a visão de enfermeiras das ESF, considerando que há o envolvimento de outros profissionais no atendimento de mulheres em situação de violência. Ainda, os resultados não podem ser generalizados, tendo vista as características das participantes e do contexto do estudo, as quais revelam singularidades.

Sugere-se, como proposta de intervenção, que profissionais de saúde e gestores se reúnam no intuito de dialogar sobre os limites que dificultam a assistência às mulheres em situação de violência e as experiências no seu atendimento. Além disso, propõe-se novas pesquisas com mulheres em situação de violência, buscando conhecer as suas percepções acerca da atuação de profissionais de saúde da atenção primária, abrindo-se assim novas perspectivas para a prevenção e o enfrentamento desta forma de violência. E, nas situações de violência, é necessário fortalecer o trabalho em rede, para que essas mulheres se sintam amparadas nos diferentes espaços multidisciplinares, contemplando suas necessidades e de sua família.

\section{Referências}

1. World Health Organization (WHO). Respect women: preventing violence against women. Geneva: World Health Organization; 2019.

2. Abrahams N, Devries K, Watts C, Pallitto C, Petzold M, Shamu S, et al. Worldwide prevalence of nonpartner sexual violence: a systematic review. Lancet [Internet]. 2014 maio [acesso em 2018 ago 17];383(9929):1648-54. Disponível em: https:/www.ncbi.nlm.nih.gov/pubmed/24529867 doi: 10.1016/S01406736(13)62243-6

3. Lima CA, Deslandes SF. Violência sexual contra mulheres no Brasil: conquistas e desafios do setor saúde na década de 2000. Saúde Soc [Internet]. 2014 [acesso em 2019 ago 17];23(3):787-800. Disponível em: 
Violência contra as mulheres: atuação da enfermeira na atenção primária à saúde | 16

http://www.scielo.br/pdf/sausoc/v23n3/0104-1290-sausoc-23-3-0787.pdf

doi:

$10.1590 /$ S010412902014000300005

4. Bandeira LM. Violência de gênero: a construção de um campo teórico e de investigação. Soc Estado [Internet]. 2014 maio-ago [acesso em 2019 ago 17];29(2):449-69. Disponível em: http://www.scielo.br/pdf/se/v29n2/08.pdf doi: 10.1590/S0102-69922014000200008

5. Brasil, Presidência da República, Secretaria Nacional de Enfrentamento à Violência contra as Mulheres (BR). Política nacional de enfrentamento à violência contra as mulheres. Brasília (DF): Secretaria Nacional de Enfrentamento à Violência contra as Mulheres; 2011.

6. Albuquerque L, Moura MAV, Queiroz ABA, Leite FMC, Silva GF. Isolamento de mulheres em situação de violência pelo parceiro íntimo: uma condição em redes sociais. Esc Anna Nery Rev Enferm [Internet]. 2017 mar [acesso em 2018 out 01];21(1):e20170007. Disponível em: http://revistaenfermagem.eean.edu.br/detalhe_artigo.asp?id=1478 doi: 10.5935/1414-8145.20170007

7. Gomes NP, Diniz NMF, Reis LA, Erdmann AL. Rede social para o enfrentamento da violência conjugal: representação de mulheres que vivenciam o agravo. Texto \& Contexto Enferm [Internet]. 2015 abr-jun [acesso em 2018 out 02];24(2):316-24. Disponível em: http://www.scielo.br/pdf/tce/v24n2/pt_01040707-tce-24-02-00316.pdf doi: 10.1590/0104-07072015002140012

8. Vieira LB, Oliveira IE, Tocantins FR, Pina-Roche F. Apoio à mulher que denuncia o vivido da violência a partir de sua rede social. Rev Latinoam Enferm [Internet]. 2015 set-out [acesso em 2018 out 02]; 23(5):865-73. Disponível em: https://www.lume.ufrgs.br/bitstream/handle/10183/129904/000977817.pdf? sequence=1 doi: 10.1590/01041169.0457 .2625

9. Arboit J, Padoin SMM, Vieira LB, Paula CC, Costa MC, Cortes LF. Atenção à saúde de mulheres em situação de violência: desarticulação dos profissionais em rede. Rev Esc Enferm USP [Internet]. 2017 [acesso em 2018 out 01];51:e03207. Disponível em: http://www.scielo.br/pdf/reeusp/v51/pt_1980-220Xreeusp-51-e03207.pdf doi: 10.1590/S1980-220X2016013603207

10. Martins LCA, Silva EB, Dilélio AS, Costa MC, Colomé ICS, Arboit J. Violência de gênero: conhecimento e conduta dos profissionais da estratégia saúde da família. Rev Gaúch Enferm [Internet]. 2018 jul [acesso em 2018 out 01];39:e2017-0030. Disponível em: http://www.scielo.br/pdf/rgenf/v39/19831447-rgenf-39-01-e2017-0030.pdf doi: 10.1590/1983-1447.2018.2017-0030

11. Lima LAA, Oliveira JC, Cavalcante FA, Santos WSV, Silva Júnior FJG, Monteiro CFS. Assistência de enfermagem às mulheres vítimas de violência doméstica. Rev Enferm UFPI [Internet]. 2017 abr-jun [acesso em 2018 out 01];6(2):65-8. Disponível em: http://www.ojs.ufpi.br/index.php/reufpi/article/view/5783 doi: $10.26694 /$ reufpi.v6i2.5783 
17 | Sehnem GD, Lopes EB, Tier CG, Ribeiro AC, Maciel VQS, Castilhos L

12. Minayo MCS. Amostragem e saturação em pesquisa qualitativa: consensos e controvérsias. Rev Pesqui Qual [Internet]. 2017 [acesso em 2019 ago 17];5(7):01-12. Disponível em: https://editora.sepq.org.br/index.php/rpq/article/view/82/59

13. Minayo MCS. O desafio do conhecimento: pesquisa qualitativa em saúde. $14^{\mathrm{a}}$ ed. São Paulo (SP): Hucitec/ABRASCO; 2014.

14. Marques SS, Riquinho DL, Santos MC, Vieira LB. Estratégias para identificação e enfrentamento de situação de violência por parceiro íntimo em mulheres gestantes. Rev Gaúch Enferm [Internet]. 2017 maio [acesso em 2018 out 01];37(3):e67593. Disponível em: http://www.scielo.br/pdf/rgenf/v38n3/01026933-rgenf-38-3-e67593.pdf doi: 10.1590/1983-1447.2017.03.67593

15. Albuquerque Netto L, Pereira ER, Tavares JMAB, Ferreira DC, Broca PV. Atuação da enfermagem na conservação da saúde de mulheres em situação de violência. REME Rev Min Enferm [Internet]. 2018 [acesso em 2019 ago 18];22:e-1149. Disponível em: http://www.reme.org.br/artigo/detalhes/1292 doi: $10.5935 / 1415-2762.20180080$

16. Santos ES, Almeida MAPT. Atendimento prestado pelos serviços de saúde à mulher vítima de violência sexual. ID On Line Rev Psicol [Internet]. 2017 maio [acesso em 2018 out 02];11(35):84-100. Disponível em: https://idonline.emnuvens.com.br/id/article/view/721/1017

17. Meneghel SN, Lerma BRL. Feminicídios em grupos étnicos e racializados: síntese. Ciênc Saúde Colet [Internet]. 2017 [acesso em 2019 ago 18];22(1):117-22. Disponível em: http://www.scielo.br/pdf/csc/v22n1/1413-8123-csc-22-01-0117.pdf doi: 10.1590/1413-81232017221.19192016

18. Brasil. Ministério da Saúde. Lei n. 10.778, de 24 de novembro de 2003. Estabelece a notificação compulsória, no território nacional, do caso de violência contra a mulher que for atendida em serviços de saúde públicos ou privados. Diário Oficial da União, Brasília (DF): Ministério da Saúde; 2003 nov 25. Seção 1, p. 11.

19. Garbin CAS, Dias IA, Rovida TAS, Garbin AJI. Desafios do profissional de saúde na notificação da violência: obrigatoriedade, efetivação e encaminhamento. Ciênc Saúde Colet [Internet]. 2015 [acesso em 2019 ago 18];20(6):1879-90. Disponível em: http://www.scielo.br/pdf/csc/v20n6/1413-8123-csc-20-061879.pdf doi: 10.1590/1413-81232015206.13442014

20. Baptista RS, Chaves OBBM, França ISX, Sousa FS, Oliveira MG, Leite CCS. Violência sexual contra mulheres: a prática de enfermeiros. Rev RENE [Internet]. 2015 abr [acesso em 2018 out 01];16(2):210-7. Disponível em: http://repositorio.ufc.br/bitstream/riufc/12654/1/2015_art_rsbaptista.pdf doi: 10.15253/2175-6783.2015000200010

21. Cordeiro KCC, Santos RM, Gomes NP, Melo DS, Mota RS, Couto TM. Formação profissional e notificação da violência contra a mulher. Rev Baiana Enferm [Internet]. 2015 jul-set [acesso em 2019 ago 
20];29(3):209-17. Disponível em: https://portalseer.ufba.br/index.php/enfermagem/article/view/13029/pdf_5 doi: 10.18471/rbe.v29i3.13029

22. Baragatti DY, Audi CAF, Melo MC. Abordagem sobre a disciplina violência em um curso de graduação em enfermagem. Rev Enferm UFSM [Internet]. 2014 jun [acesso em 2018 out 01];4(2):470-7. Disponível em: https://periodicos.ufsm.br/reufsm/article/view/11265/pdf doi: 10.5902/2179769211265

23. Holanda ER, Holanda VR, Vasconcelos MS, Souza VP, Galvão MTG. Fatores Associados à violência contra as mulheres na atenção primária de saúde. Rev Bras Promoç Saúde [Internet]. 2018 mar [acesso em 2018 out 01];31(1):1-9. Disponível em: http://periodicos.unifor.br/RBPS/article/view/6580/pdf doi: $10.5020 / 18061230.2018 .6580$

24. Ferraz MIR, Labronici LM. Fragmentos de corporeidades femininas vítimas de violência conjugal: uma aproximação fenomenológica. Texto \& Contexto Enferm [Internet]. 2015 jul-set [acesso em 2018 out 01];24(3):842-9. Disponível em: http://www.scielo.br/pdf/tce/v24n3/pt_0104-0707-tce-24-03-00842.pdf doi: 10.1590/0104-07072015003030014

25. Cortes LF, Padoin SMM, Kinalski DDF. Instrumentos para articulação da rede de atenção às mulheres em situação de violência: construção coletiva. Rev Gaúch Enferm [Internet]. 2016 out [acesso em 2018 out 01];37:e2016-0056. Disponível em: http:/www.scielo.br/pdf/rgenf/v37nspe/0102-6933-rgenf1983-14472016esp2016-0056.pdf doi: 10.1590/19831447.2016.esp.2016-0056

\section{Autor correspondente}

Graciela Dutra Sehnem

E-mail: graci_dutra@yahoo.com.br

Endereço: Av. Rodolfo Behr 132 ap 201 Bairro: Camobi Santa Maria/RS

CEP: 97.105-440

\section{Contribuições de Autoria}

1 - Graciela Dutra Sehnem

Concepção e planejamento do projeto de pesquisa; análise e interpretação dos dados; redação e revisão crítica.

2 - Eveline Barbosa Lopes

Concepção e planejamento do projeto de pesquisa; obtenção ou análise e interpretação dos dados; redação.

3 - Cenir Gonçalves Tier

Análise e interpretação dos dados; redação e revisão crítica.

4 - Aline Cammarano Ribeiro

Redação e revisão crítica. 
19 | Sehnem GD, Lopes EB, Tier CG, Ribeiro AC, Maciel VQS, Castilhos L

5 - Victória de Quadros Severo Maciel

Análise e interpretação dos dados, redação.

6 - Lara Castilhos

Redação e revisão crítica.

\section{Como citar este artigo}

Sehnem GD, Lopes EB, Tier CG, Ribeiro AC, Maciel VQS, Castilhos L. Violência contra as mulheres: atuação da enfermeira na atenção primária à saúde. Rev. Enferm. UFSM. 2019 [Acesso em: Anos Mês Dia];vol.9, e62: 1-19. DOI:https://doi.org/10.5902/2179769235061 